\title{
Systems metabolic engineering for citric acid production by Aspergillus niger in the post-genomic era
}

\author{
Zhenyu Tong ${ }^{1 \dagger}$, Xiaomei Zheng ${ }^{2,3+} \mathbb{C}^{0}$, Yi Tong $^{4}$, Yong-Cheng Shi ${ }^{1}$ and Jibin Sun ${ }^{2,3^{*}}$
}

\begin{abstract}
Citric acid is the world's largest consumed organic acid and is widely used in beverage, food and pharmaceutical industries. Aspergillus niger is the main industrial workhorse for citric acid production. Since the release of the genome sequence, extensive multi-omic data are being rapidly obtained, which greatly boost our understanding of the citric acid accumulation mechanism in A. niger to a molecular and system level. Most recently, the rapid development of CRISPR/Cas9 system facilitates highly efficient genome-scale genetic perturbation in A. niger. In this review, we summarize the impact of systems biology on the citric acid molecular regulatory mechanisms, the advances in metabolic engineering strategies for enhancing citric acid production and discuss the development and application of CRISPR/ Cas9 systems for genome editing in A. niger. We believe that future systems metabolic engineering efforts will redesign and engineer A. niger as a highly optimized cell factory for industrial citric acid production.
\end{abstract}

Keywords: Aspergillus niger, Citric acid, Systems biology, Metabolic engineering, CRISPR/Cas9 genome editing

\section{Background}

Citric acid (2-hydroxy-propane-1,2,3-tricarboxylic acid) is known as an intermediate of the tricarboxylic acid cycle that is used to release energy from carbohydrates, fats, and proteins via the oxidation of acetyl-CoA [1, 2]. Citric acid is also the most important bulk product in the organic acid industry, owing to its ubiquitous applications, including beverage and food, pharmaceutical, detergents, cosmetics and organic chemical industries [1, 2]. Citric acid is widely used as an ingredient in carbonated drinks, an acidulant, and flavor additive, due to its pleasant taste, palatability and low toxicity. Moreover, citric acid is also used as a chelating agent and detergent for metal finishing and cleaning, lubricants, animal feeds and plasticizers. The various industrial application promotes the worldwide market of citric acid reached up to 1.7 million tons in 2007, with an annual increase of $3.5-4.0 \%$ [3].

\footnotetext{
*Correspondence: sun_jb@tib.cas.cn

†Zhenyu Tong and Xiaomei Zheng contributed equally to this work

${ }^{2}$ Tianjin Institute of Industrial Biotechnology, Chinese Academy

of Sciences, Tianjin 300308, People's Republic of China

Full list of author information is available at the end of the article
}

The high commercial interest has attracted numerous scientists to devote themselves to citric acid over-producing strain development since the last century. Many microorganisms have been discovered to accumulate citric acid including Absidia sp., Acremonium, Botrytis, Eupenicillium, Penicillium, and some Aspergillus sp., such as Aspergillus niger, Aspergillus awamori, Aspergillus nidulans, Aspergillus luchensis, and Aspergillus flavus [4]. Besides filamentous fungi, some bacteria and yeast strains are also found to produce citric acid. Bacteria have been reported, including Bacillus sp., Brevibacterium sp., Corynebacterium sp., Klebsiella sp., and Pseudomonas sp. amongst others [3]. Yeast strains are found to be potential producers from a variety of carbon sources, such as Candida sp. and Yarrowia sp. [4]. However, due to large amounts of by-product iso-citric acid during yeast fermentation [4], approximately $80 \%$ of world-wide citric acid is produced by submerged fermentation using $A$. niger [5].

Although many microorganisms could be utilized for citric acid production, since 1917, Currie discovered that some $A$. niger strains excreted large amounts of citric acid at the initial $\mathrm{pH}$ of 2.5 [4]. A. niger has been the 
main industrial workhorse owing to its unique inherent physiological characters and better fitness for industrial fermentation [2, 4, 6]. A. niger has powerful polymer degrading enzyme systems to hydrolyze many polymeric substrates, enabling to rapidly grow and ferment on a variety of low-cost raw materials such as corn meal and molasses [7]. A. niger demonstrates great robustness to extreme acid environments, leading to outcompeting other rival microorganisms and reducing contamination risk. The high citric acid yield of $0.95 \mathrm{~g} / \mathrm{g}$ supplied sugar can be achieved with the assistance of fermentation optimization [2]. However, the theoretical citric acid yield was $1.067 \mathrm{~g} / \mathrm{g}$ glucose [4], thereby a gap still exists between the practical yield of citric acid and theoretical yield. Under the increasingly fierce competition, demanding for high yield, titer and productivity are crucial for strain development, ultimately, to reduce production costs and minimize environmental problems, as successfully achieved in Thermotoga maritima by increasing the $\mathrm{H}_{2}$ yield even beyond the previously predicted biological limit [8]. Nevertheless, until recently, the strain development efforts commonly occur through random mutagenesis and screening processes that supplied several mutants with great industrial performance, which constitutes a bottleneck for further improvement, as often the inherent accumulation of detrimental mutations and the precise mutations that lead to strain improvement remain unknown [9]. Obviously, the comprehensive understanding of the complex pathway network with metabolic and transcriptional regulation is prerequisite to achieve strain engineering through a global genome modification $[10,11]$.

Since 2007, the public release of genome data for $A$. niger strains brought the study of $A$. niger into the postgenomic era [12]. With the rapid development of systems biology and genome editing techniques, the underlying molecular mechanism of $A$. niger citric acid fermentation can gradually be unveiled, and systems metabolic engineering is currently being used to redesign and optimize $A$. niger as a cell factory. Until now, no review has focused on how advances in systems biology and metabolic engineering of $A$. niger are enhancing citric acid production. In this review, we summarize the impact of systems biology on understanding the citric acid molecular regulatory mechanisms, the existing metabolic engineering strategies implemented to improve citric acid production and review the development of CRISPR/Cas9 systems for genome editing in $A$. niger. We also proposed future prospects in the systems metabolic engineering cycle, combining the genome information, modern bioinformatics approaches and efficient molecular genetic manipulation tools, to design and engineer $A$. niger as a highly optimized cell factory for improving the yield, titer and productivity with reduced costs and improved environmental sustainability.

\section{Systems biology boosts the understanding of citric acid metabolic regulation in A. niger}

Citric acid is the first intermediate of the TCA cycle, and is synthesized by the condensation of acetyl-coenzyme $\mathrm{A}$ (acetyl-CoA) and oxaloacetate moiety [1]. Acetyl-CoA is converted from pyruvate with $1 \mathrm{~mol} \mathrm{CO}$ released in the mitochondria, while oxaloacetate is formed by pyruvate carboxylation from pyruvate with $1 \mathrm{~mol} \mathrm{CO}_{2}$ fixation in the cytoplasm. Oxaloacetate is subsequently converted into malic acid and enters the mitochondria through a malate-citrate shuttle. Malic acid is reconverted into oxaloacetate and oxaloacetate takes part in citric acid synthesis. One mole glucose is converted into $1 \mathrm{~mol}$ citric acid with $1 \mathrm{~mol}$ of ATP and $3 \mathrm{~mol}$ of nicotinamide adenine dinucleotide (NADH), resulting in the maximum theoretical yield of $1.067 \mathrm{~g} / \mathrm{g}$ glucose [4].

As an intermediate of the TCA cycle, citric acid is commonly catabolized by cis-aconitase, and citrate and ATP usually have feedback inhibition against the glycolysis pathway. Nevertheless, A. niger is capable of citric acid accumulation in large amounts by an active glycolytic pathway. The unique citric acid metabolism regulation in $A$. niger has attracted much interest, and several excellent reviews have discussed the biochemical mechanisms before the $A$. niger genome release [1, 2, 4]. Multi-omics data of $A$. niger, including genomics, transcriptomics, proteomics and metabolomics, which are being rapidly obtained and boost our understanding of $A$. niger further to a system and molecular level. The impact of these datasets is discussed in detail in the subsequent section.

\section{Genomics}

The genome contains all the genetic information of an organism, and genome sequencing paves the way for all genes structure and function analyses in addition to the generation of genome-scale metabolic networks. Until now, several genomes of $A$. niger stains with different phenotypes have been submitted in the Genome database of National Center for Biotechnology Information (NCBI, Additional file 1: Table S1). The first genome sequence of an $A$. niger strain, an industrial glucoamylase producer CBS513.88, was published in 2007 [12]. Next followed comparative genomics analyses, for example, the wild type citric acid producer ATCC1015 compared with CBS513.88 [13], and citric acid over-producer H915-1 compared with two degenerated isolates L2 and A1 [14].

Comparative genomics generates new insights to identify the relationship between the genotype and phenotype and uncover the diversity of the strains 
with specific traits. Specifically, compared to enzyme producer CBS513.88, the genome of the acidogenic wild-type strain ATCC1015 contained about 510 unique genes and a large number of polymorphisms $(8 \pm 16 \mathrm{SNPs} / \mathrm{kb})$ [13]. The unique genes were $396 / 510$ evenly distributed over the seven chromosomes of CBS513.88 and ATCC1015, respectively. Remarkably, unique genes in CBS513.88 included two alphaamylases, which were horizontally transferred from Aspergillus oryzae to give the amylase over-production phenotype to CBS513.88 [13]. Additionally, the unique genes in ATCC1015 were not directly relevant to citric acid production. There were $3 / 4$ unique putative polyketide synthase encoding genes found in CBS513.88/ ATCC1015, which likely explains the different secondary metabolites between the strains [13]. Many mutations with SNPs were found to be relevant for citric acid production, whose function enriched in the plasma membrane-bound ATPase, the $\gamma$-aminobutyric acid (GABA) shunt, the TCA cycle, and electron transport chain [10], giving novel insights into potential genome engineering targets.

These comparative genomic studies between different industrial isolates have been further supplemented by genomic profiling of mutant isolates and progenitor strains, which has also been useful for predicting key molecular aspects of citric acid production. For example, comparative genomics of three $A$. niger strains with different citrate production efficiencies and mycelial pellets morphology was analyzed [14]. A. niger H915-1 exhibited the highest citrate titer of $157 \mathrm{~g} / \mathrm{L}$ and the yield of $0.98 \mathrm{~g} / \mathrm{g}$ total sugar in $85 \mathrm{~h}$ with compact pellets and short, swollen hyphal branches, whereas the degenerated isolates $\mathrm{A} 1$ and $\mathrm{L} 2$ produced $117 \mathrm{~g} / \mathrm{L}$ in $92 \mathrm{~h}$ with less hyphal branch in compact pellets, and $76 \mathrm{~g} / \mathrm{L}$ in $160 \mathrm{~h}$ with mycelial clumps, respectively [14]. Compared to two mutant strains A1 and L2, the most notable mutated genes in hyper-producer H915-1 were found to encode a succinate-semialdehyde dehydrogenase involved in GABA shunt, and an aconitase family protein, which may directly influence the citric acid production [14]. The mycelial pellet morphology is proven to dramatically affect the citric acid fermentation. Interestingly, the hydrophobin and melanin biosynthesis pathway involved in conidial and germ tube aggregation showed no difference among these three strains, while a cell wall protein was absent in H9151 , which might be relevant to the morphogenesis [14]. These discoveries between the mutant isolates provide further possible gene targets for strain improvement, e.g. genes encoding succinate-semialdehyde dehydrogenase, aconitase and cell wall protein.

\section{Transcriptomics}

Transcriptomics is an important technique in functional genomics of $A$. niger. Before the availability of genome data, the first DNA microarray study in $A$. niger only investigated the transcription change of 15 genes [15]. In 2008, Andersen et al. [16] developed a tri-species Aspergillus microarray for comparative transcriptomics of $A$. niger, $A$. nidulans and $A$. oryzae. With the availability of microarrays, Salazar et al. [17] elucidated the diversity of glycerol metabolism transcriptional regulation in Aspergilli species. Comparative transcriptome has also been applied for unveiling the notable diversity between CBS513.88 and ATCC1015 [13]. Among over 10,000 genes, about 4800 genes showed different transcriptional level between these two strains growing on the same condition. The up-regulated gene cohort in ATCC1015 was enriched in the GO biological functions of electron transport, carbohydrate transport and organic acid transport, ultimately suggesting that these candidate genes could be targeted by over-expression technology to improve citric acid production.

Compared to DNA microarray technologies, RNA sequencing (RNA-seq) is increasingly used for transcriptome analysis, due to its higher sensitivity, accuracy and resolution [18]. After the first transcriptome analysis of the Aspergillus genus using RNA-seq was performed in A. oryzae [19], Delmas et al. [20] also assessed the genome-wide transcriptional responses to lignocellulose in $A$. niger via RNA-seq. Since then, RNA-seq has been widely used in global gene expression profiling to investigate the transcription response and regulation of $A$. niger, including carbon source utilization and regulation [21-24], conidial and mycelial development [25, 26], cell wall biosynthesis $[27,28]$, secondary metabolite gene cluster expression $[29,30]$ and organic acid metabolism $[14,31-33]$. Dynamic transcriptomics enables the profiling gene expression across industrially relevant time frames using RNA-seq, shedding light on the transcriptional regulatory mechanisms and ultimately leading to target genes for engineering. Yin et al. [14] obtained the transcriptome data of H915-1 during citric acid fermentation and found that 479 genes showed significant transcription regulation, which involved in the central metabolic pathway, GABA shunt pathway and transporters. With regards to glycolysis in this dataset, only a gene encoding a triose phosphate isomerase was up-regulated, and pyruvate kinase was down-regulated, while most enzymes in the TCA cycle were down-regulated. Compared at the initial stage, ATP-citrate lyase was found to be up-regulated about sevenfold at the citric acid accumulation stage, possibly to generate oxaloacetate from citrate, which then enters the mitochondria and TCA cycle. An additional effect of this use of ATP could be the 
de-repression of the EMP pathway in an ATP futile cycle, as ATP is known to inhibit enzymes in this pathway, such as the phosphofructokinase (PFK). Taken together, these studies demonstrate how transcriptomic studies have given insight on key traits, citric acid over-production, in the lifestyle and differentiation of $A$. niger.

\section{Proteomics}

Similar to transcriptomics, proteomics is an essential component of systems biology, which enables the qualitative and quantitative assessment of the entire proteins of an organism under different conditions. Lu et al. [34] collected the intra- and extracellular $A$. niger proteome under different carbon substrate using 2-D gel electrophoresis/MALDI-TOF and nano-HPLC MS/MS and found that the secretome was dramatically influenced by the extracellular carbon substrate. Elsewhere, Adav et al. [35] analyzed the $A$. niger protein secretion profile using iTRAQ quantitative proteomics and demonstrated that 102 secreted enzymes ensured the powerful capability and potential of polymer degradation. Moreover, membrane-associated proteomic analysis has been developed to identify the new transporters. Sloothaak analyzed the plasmalemma proteomics under different glucose concentration with a hidden Markov model (HMM) and identified two high-affinity glucose transporter MstG and MstH [36]. They further identified the first eukaryotic L-rhamnose transporter RhtA [37]. These studies provide new strategies to identify the new transporters and improve the transport efficiency of substrate and product.

\section{Metabolomics and fluxomics}

Metabolomics is an important potential tool for industrial biotechnology: uncovering global metabolite profiles, identifying the biosynthetic intermediates and metabolic bottlenecks, elucidating phenotype differentiation, and also previously unknown pathways [38]. A significant body of work has been invested by the metabolomics community for standardizing experimental protocols for maximum reproducibility and non-selective sample preparation methods. These methodological and technical studies, including quantitative assessment of various sampling strategies, quenching approaches, and extraction techniques, are important prerequisites for generating high-quality datasets. Variations in these protocols can dramatically influence the metabolite data quality and their downstream interpretation [39]. Several studies aim to establish reliable and efficient sample preparation methods for $A$. niger metabolomics [40-42].

Early investigations into $A$. niger metabolomics adopted $-45{ }^{\circ} \mathrm{C} 60 \%$ methanol quenching which had previously been applied in yeast [40]. Recently, many groups have demonstrated high methanol concentrations caused lower recovery of intracellular metabolites, and consequently $-20{ }^{\circ} \mathrm{C} 40 \%$ methanol was preferentially used as a quenching solution [42]. However, after comprehensively comparing the impact of fast filtration and cold methanol quenching approaches, we discovered that fast filtration with liquid nitrogen is a further improvement for quenching the cellular metabolism of $A$. niger, given its minimal cell damage, high intracellular metabolite recovery and relatively efficient quenching efficiency [43].

Few intracellular metabolite extraction methods have been used in $A$. niger, such as chloroform/methanol/ buffer (CM) [40], or boiling ethanol (BE) [42]. A limitation to these approaches was demonstrated by Jernejc et al. who uncovered that BE displayed lower extraction efficiency of three organic acids (pyruvate, malate and 2-oxoglutarate) compared with the traditional acid and alkaline treatments [41]. Given the extreme acidic and alkalinic extraction methods were not compatible with MS-based detection and global metabolomics analysis, we have recently systemically evaluated seven metabolite extraction methods and unveiled that acetonitrile/ water $(1: 1, v / v)$ at $-20^{\circ} \mathrm{C}$, combined with boiling ethanol extraction protocols based liquid chromatography-tandem mass spectrometry (LC-MS/MS), showed unbiased metabolite profiling. With aid of this optimal LC-MS/ MS metabolomics pipeline, we investigated the dynamics of the metabolite profile over time for a citrate overproducing $A$. niger isolate. The metabolomics analyses suggest that high Embden-Meyerhof pathway (EMP) flux and high level of citric acid precursors ensure citrate accumulation [43]. For example, at the citric acid rapid production stage, the intracellular level of pyruvate and oxaloacetate increased by 5.03 - and 12.42 -fold, respectively [43].

Similar to the metabolomics, fluxomics analysis is also a powerful strategy to unveil the metabolic properties and in vivo flux distribution in filamentous fungi such as A. niger. ${ }^{13} \mathrm{C}$ metabolic flux analysis, for example, has been utilized to investigate the metabolic difference in mutant enzyme over-producing strains [44-47]. Pedersen et al. [45] found that the disruption of oahA gene encoding oxaloacetate acetylhydrolase in a glucoamylaseproducing strain did not influence the central carbon metabolism and metabolic flux distribution, while Driouch et al. [46] discovered that overexpression of fructofuranosidase caused the activation of cytosolic pentose phosphate pathway (PPP) and mitochondrial malic enzyme, suggesting the NADPH supply played an essential role in fructofuranosidase production. Lu et al. [47] also found that the carbon flux to PPP increased in a high glucoamylase-producing strain, compared to the wild 
type strain CBS513.88. Moreover, combined with the isotope-assisted metabolomics, they found that the secretion of oxalic acid and citric acid resulted from the higher redox state caused by the imbalance of NADH regeneration and consumption in CBS513.88. Taken together, the integrated analysis of metabolomics and fluxomics will shed light on dynamic changes of metabolites pool and kinetic data of intracellular enzymes, and ultimately, for identifying the limiting metabolic steps.

\section{Genome-scale metabolic modeling}

With the availability of massive multi-omics data [48], genome-scale metabolic modeling plays an important role in integrating multi-omics information and quantitatively analyzing phenotypes, which thereby allows the a priori prediction of an organism's behavior and the elucidation of molecular mechanisms which underpin these phenotypes [49]. Several metabolic networks of $A$. niger have been developed to uncover the key aspects of citric acid over-production [50-55]. Sun et al. [53] developed the first genome-scale metabolic network of $A$. niger based on the genome information of CBS513.88 and ATCC9029, including enzymes with 988 unique EC numbers, 2443 reactions and 2349 metabolites. Additional copies of alternative mitochondrial oxidoreductase (AOX) and citrate synthase (CS) encoding genes were found in $A$. niger, which might contribute to the citric acid accumulation. Consequently, these open reading frames constitute outstanding candidates for rational strain engineering using the extensive $A$. niger toolkit [56].

Another genome-scale metabolic model $i$ MA871 of $A$. niger was reconstructed based on the genome of ATCC1015, including 1190 reactions [51]. Compared to the genome-scale metabolic network described above, this metabolic model is more reliable, including the information of the subcellular localization and transport, which is very important for model simulation. In another study, a dynamic metabolic model was developed by a novel modeling method of dynamic flux balance analysis (dFBA), with the time-course fermentative series of citric acid production, which provided a powerful platform to accurately explore the effects of genetic changes on citric acid fermentation in a dynamic manner [55]. Upton et al. [55] demonstrated that the citric acid accumulation was relevant to the polyphosphate hydrolysis regulation and diauxic growth behavior. The constraint on polyphosphate hydrolysis played a crucial role to initiate the citric acid accumulation by limiting cell growth. These data suggested that the genes involved in polyphosphate and energy metabolism could be new targets to uncover the metabolic change for citric acid accumulation.
In summary, the combination of systems biology datasets from the highlighted studies, key attributes of citric acid accumulation mechanism in $A$. niger can be summarized as follows: efficient carbon utilization and transport resulted from powerful hydrolytic enzyme and glucose transport system, high glycolysis flux resulted from the relief of feedback inhibition of ATP and citrate, high C4 anaplerotic activity catalyzed by pyruvate carboxylase to secure precursor supplement, low cis-aconitase and isocitrate dehydrogenase activity to prevent citrate degradation, efficient alternative respiratory chain mediated by AOX to accelerate NADH oxidation and $\mathrm{NAD}^{+}$regeneration with less energy production, ATP futile cycle and consumption catalyzed by ACL, $\mathrm{Mn}^{2+}$ deficiency to keep high glycolysis flux but low citrate degradation flux via TCA cycle, and compact mycelial pellets to secure the oxygen transfer by lower the viscosity of the fermentation broth, and high acid resistance mediate by GABA shunt. With the assistance of systems biology, especially the genome-scale metabolic modeling, it is now possible to identify bottlenecks as targets for $A$. niger metabolic engineering, which efforts to design and optimize new stains capable of enhanced citric acid production on lowcost feedstocks, including agro-industrial wastes and lignocellulose biomass, with reduced energy consumption and environmental contamination.

\section{Metabolic engineering improves citric acid production in A. niger}

Along with further deep understanding of citric acid metabolism regulation, instead of traditional mutagenesis, rational metabolic engineering has gradually become a powerful approach to improve citric acid production. The metabolic engineering strategies are summarized in Fig. 1 and Table 1. Compared to the few strategies, e.g. overexpression of invertase [57], inulinase [58], isocitrate lyase [59] and pyruvate carboxylase [60, 61], used in the yeast strain Y. lipolytica (Additional file 1: Table S2), the metabolic engineering strategies applied in $A$. niger are more comprehensive, including the enhancement of carbon source utilization, citric acid synthesis, precursor supplements and alternative respiratory chain, the relief of feedback inhibition, the removal of by-products, and so on. Some cases involved in universal strategies, i.e. enhancing the citric acid synthesis [62,63] and eliminating by-product formation [64], have been reported in the previous review [65]. Herein, we summarized the current metabolic engineering strategies for citric acid production.

\section{Engineering carbon utilization}

Aspergillus niger is able to secrete a cocktail of hydrolytic enzymes to rapidly degrade complex polymers 


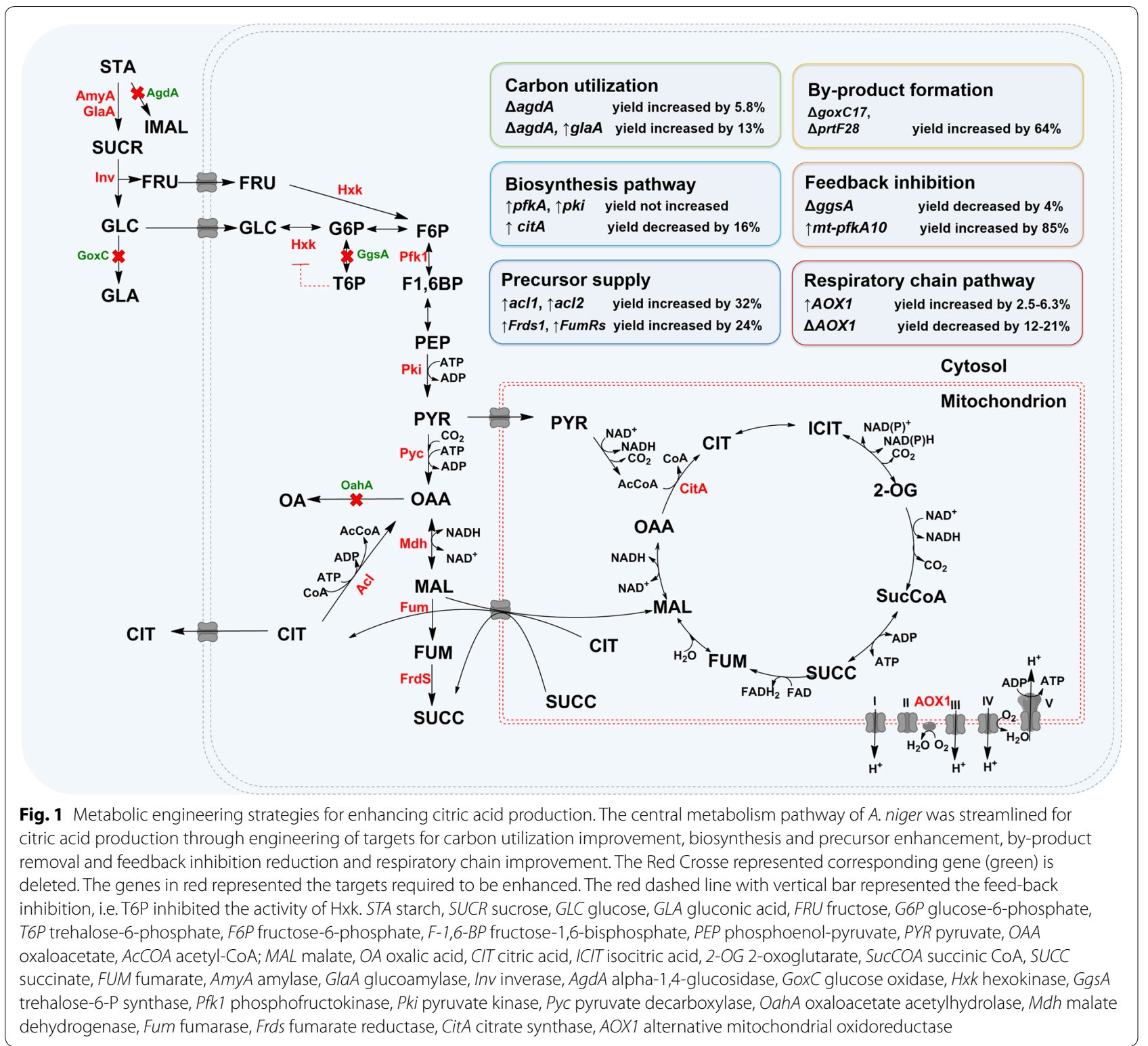

found in cheap substrates (such as feedstock) into monosaccharides. However, when liquefied corn starch was utilized for citric acid production, about $2 \%-3 \%$ of the residual sugar remains at the end of the fermentation process. Owing to citric acid production scale of about 1.7 million tons, the residual sugar would account for the annual loss of 150 thousand tons of corn and lead to great environmental pressure world-wide [66]. Therefore, the reduction of residual sugar plays an important role in improving the efficiency of citric acid production. Iso-maltose, synthesized by $\alpha$-glucosidase, is the main component of the residual sugar in citric acid fermentation broth [66]. Deletion of $\alpha$-glucosidases encoding gene
agdA efficiently reduced the isomaltose concentration [66]. Combined with the over-expression of glucoamylase glaA, the residual sugar reduced about $88.2 \%$ and the citric acid production increased $16.9 \%$, reaching up to $185.7 \mathrm{~g} / \mathrm{L}$ [66]. The multi-copies of the glaA gene under the native PagdA promoter improved the extracellular glucoamylase activity by $34.5 \%$ [66]. The glucoamylase activity did not strictly positive correlate with citric acid yield, but it significantly influences the saccharification when using corn starch as the raw carbon source [66]. Thus, the increase of glucoamylase activity resulted in higher citric acid production, and constitutes a promising avenue for further biotechnological research. 
Table 1 Metabolic engineering strategies for enhancing citric acid production in $A$. niger

\begin{tabular}{|c|c|c|c|c|c|c|c|c|}
\hline Strain & $\begin{array}{l}\text { Engineering } \\
\text { strategy }\end{array}$ & $\begin{array}{l}\text { Original } \\
\text { strain }\end{array}$ & Titer $(\mathbf{g} / \mathbf{L})$ & $\begin{array}{l}\text { Productivity } \\
\text { (g/L/h) }\end{array}$ & $\begin{array}{l}\text { Yield (g/g } \\
\text { sugar } \\
\text { consumed) }\end{array}$ & By-product & $\begin{array}{l}\text { Fermentation } \\
\text { condition }\end{array}$ & References \\
\hline \multicolumn{9}{|c|}{ Engineering carbon utilization } \\
\hline TNA 101 $\triangle \mathrm{agdA}$ & $\triangle a g d A$ & CGMCC10142 & $172.7, \uparrow 8.68 \%$ & 2.40 & $0.96^{\mathrm{a}}$ & $\begin{array}{l}\downarrow 52.95 \% \\
\text { (residual } \\
\text { sugar) }\end{array}$ & $\begin{array}{l}\text { Liquefied corn } \\
\text { medium, } \\
180 \mathrm{~g} / \mathrm{L} \text { total } \\
\text { sugar, } 72 \mathrm{~h}\end{array}$ & {$[66]$} \\
\hline OG1 & $\begin{array}{r}\Delta a g d A, \\
\uparrow g l a A\end{array}$ & CGMCC10142 & $185.7, \uparrow 16.87 \%$ & 2.58 & $1.03^{\mathrm{a}}$ & $\begin{array}{l}\downarrow 88.24 \% \\
\quad \text { (residual } \\
\text { sugar) }\end{array}$ & $\begin{array}{l}\text { Liquefied corn } \\
\text { medium, } \\
180 \mathrm{~g} / \mathrm{L} \text { total } \\
\text { sugar, } 72 \mathrm{~h}\end{array}$ & {$[66]$} \\
\hline \multicolumn{9}{|c|}{ Enhancing citric acid biosynthesis pathway } \\
\hline $50-2-12$ & $\uparrow p f k A, \uparrow p k i$ & $\begin{array}{l}\text { NW129/ } \\
\text { NW131 }\end{array}$ & 55 , no change & 0.33 & $0.64^{b}$ & - & $\begin{array}{l}\text { Synthetic } \\
\text { medium, } \\
140 \mathrm{~g} / \mathrm{L} \text { glucose, } \\
168 \mathrm{~h}\end{array}$ & [62] \\
\hline $55-14$ & $\uparrow c i t A$ & $\begin{array}{l}\text { NW129/ } \\
\text { NW131 }\end{array}$ & $46, \downarrow 16.36 \%$ & 0.27 & $0.52^{\mathrm{b}}$ & - & $\begin{array}{l}\text { Synthetic } \\
\text { medium, } \\
140 \mathrm{~g} / \mathrm{L} \text { glucose, } \\
168 \mathrm{~h}\end{array}$ & [63] \\
\hline \multicolumn{9}{|c|}{ Enhancing precursor supplement pathway } \\
\hline$a c 11-a c 12$ & $\uparrow a c l 1, \uparrow a c l 2$ & ATCC1015 & $42, \uparrow 32 \%$ & 0.35 & $0.42^{\mathrm{a}}$ & - & $\begin{array}{l}\text { Synthetic } \\
\text { medium, } \\
100 \mathrm{~g} / \mathrm{L} \text { glucose, } \\
120 \mathrm{~h}\end{array}$ & [67] \\
\hline$\Delta \mathrm{acl}$ & $\triangle a c l 1$ & AB4.1 & increased & - & $0.043^{b}$ & $\begin{array}{c}\text { Succinate, } \\
\text { Oxalate, } \\
\text { Glycerol }\end{array}$ & - & {$[68]$} \\
\hline Frds (V)-FumRs & $\begin{array}{l}\uparrow \text { Frds1, } \\
\uparrow \text { FumRs }\end{array}$ & N402 & $29.5, \uparrow 59.46 \%$ & 0.10 & $0.46^{\mathrm{b}}$ & Oxalate & $\begin{array}{l}\text { Synthetic } \\
\text { medium, } 50 \mathrm{~g} / \mathrm{L} \\
\text { glucose, } 14 \text { days }\end{array}$ & [69] \\
\hline \multicolumn{9}{|c|}{ Removal of by-product formation } \\
\hline NW185 & $\begin{array}{r}\triangle 90 \times C 17 \\
\triangle p r t F 28\end{array}$ & NW131 & $90, \uparrow 63.64 \%$ & 0.375 & $0.64^{\mathrm{a}}$ & No oxalate & $\begin{array}{l}\text { Synthetic } \\
\text { medium, } \\
140 \mathrm{~g} / \mathrm{L} \text { glucose, } \\
240 \mathrm{~h}\end{array}$ & [64] \\
\hline \multicolumn{9}{|c|}{ Reducing feedback inhibition } \\
\hline$\Delta 1-3$ & $\triangle g g s A$ & ATCC11414 & $115, \downarrow 4.17 \%$ & - & $0.82^{\mathrm{a}}$ & - & $\begin{array}{l}\text { Shu and Johnson } \\
\text { medium, } \\
140 \mathrm{~g} / \mathrm{L} \text { sucrose }\end{array}$ & [71] \\
\hline TE23 & $\uparrow m t-p f k A 10$ & A158 & $\sim 120, \uparrow \sim 85 \%$ & 0.4 & $0.80^{\mathrm{a}}$ & - & $\begin{array}{l}\text { Synthetic } \\
\text { medium, } \\
150 \mathrm{~g} / \mathrm{L} \\
\text { sucrose, } \sim 300 \mathrm{~h}\end{array}$ & {$[72]$} \\
\hline \multicolumn{9}{|c|}{ Engineering $\mathrm{Mn}^{2+}$ response and morphology } \\
\hline Brsa-25-3 & $\downarrow$ Brsa-25 & ATCC11414 & $2.5, \uparrow \sim 35 \%$ & 0.042 & - & - & $\begin{array}{l}\text { Synthetic } \\
\text { medium, } \\
140 \mathrm{~g} / \mathrm{L} \text { glucose, } \\
60 \mathrm{~h} \text { in tested } \\
\text { tube }\end{array}$ & [77] \\
\hline $\operatorname{chs}-3$ & $\downarrow$ chs $C$ & CBS513.88 & $180.3, \uparrow 3.56 \%$ & 2.50 & $1.02^{\mathrm{a}}$ & - & $\begin{array}{l}\text { Liquefied corn } \\
\text { medium, } \\
177 \mathrm{~g} / \mathrm{L} \text { total } \\
\text { sugar, } 72 \mathrm{~h}\end{array}$ & [78] \\
\hline \multicolumn{9}{|c|}{ Regulating the respiratory chain } \\
\hline CGMCC5751 & $\begin{array}{l}\text { Adding } \\
0.2 \mathrm{mg} / \mathrm{L} \\
\text { antimy- } \\
\text { cin A }\end{array}$ & CGMCC5751 & $\begin{array}{l}\text { 151.67, } \\
\uparrow 19.89 \%\end{array}$ & 2.11 & $0.82^{\mathrm{a}}$ & - & $\begin{array}{l}\text { Liquefied corn } \\
\text { medium, } \\
184 \mathrm{~g} / \mathrm{L} \text { total } \\
\text { sugar, } 72 \mathrm{~h}\end{array}$ & {$[75]$} \\
\hline
\end{tabular}


Table 1 (continued)

\begin{tabular}{|c|c|c|c|c|c|c|c|c|}
\hline Strain & $\begin{array}{l}\text { Engineering } \\
\text { strategy }\end{array}$ & $\begin{array}{l}\text { Original } \\
\text { strain }\end{array}$ & Titer (g/L) & $\begin{array}{l}\text { Productivity } \\
\text { (g/L/h) }\end{array}$ & $\begin{array}{l}\text { Yield (g/g } \\
\text { sugar } \\
\text { consumed) }\end{array}$ & By-product & $\begin{array}{l}\text { Fermentation } \\
\text { condition }\end{array}$ & References \\
\hline CGMCC5751 & $\begin{array}{l}\text { Adding } \\
0.1 \mathrm{mg} / \mathrm{L} \\
\text { DNP }\end{array}$ & CGMCC5751 & $135.78, \uparrow 7.32 \%$ & 1.89 & $0.74^{\mathrm{a}}$ & - & $\begin{array}{l}\text { Liquefied corn } \\
\text { medium, } \\
184 \mathrm{~g} / \mathrm{L} \text { total } \\
\text { sugar, } 72 \mathrm{~h}\end{array}$ & [75] \\
\hline CGMCC10142-72 & $\uparrow A O X 1$ & CGMCC10142 & $163.1, \uparrow 2.52 \%$ & 2.27 & $0.89^{\mathrm{a}}$ & - & $\begin{array}{l}\text { Liquefied corn } \\
\text { medium, } \\
184 \mathrm{~g} / \mathrm{L} \text { total } \\
\text { sugar, with } \\
0.2 \mu \mathrm{g} / \mathrm{mL} \text { anti- } \\
\text { mycin } \mathrm{A}, 72 \mathrm{~h}\end{array}$ & {$[76]$} \\
\hline CGMCC10142-102 & $\uparrow A O X 1$ & CGMCC10142 & $169.1, \uparrow 6.29 \%$ & 2.35 & $0.92^{\mathrm{a}}$ & - & $\begin{array}{l}\text { Liquefied corn } \\
\text { medium, } \\
184 \mathrm{~g} / \mathrm{L} \text { total } \\
\text { sugar, with } \\
0.2 \mu \mathrm{g} / \mathrm{mL} \text { anti- } \\
\text { mycin A, } 72 \mathrm{~h}\end{array}$ & {$[76]$} \\
\hline CGMCC10142-3-4 & $\triangle A O X 1$ & CGMCC10142 & $140.1, \downarrow 11.95 \%$ & 1.95 & $0.76^{\mathrm{a}}$ & - & $\begin{array}{l}\text { Liquefied corn } \\
\text { medium, } \\
184 \mathrm{~g} / \mathrm{L} \text { total } \\
\text { sugar, with } \\
0.2 \mu \mathrm{g} / \mathrm{mL} \text { anti- } \\
\text { mycin A, } 72 \mathrm{~h}\end{array}$ & {$[76]$} \\
\hline CGMCC10142-4-10 & $\triangle A O X 1$ & CGMCC10142 & $125.6, \downarrow 20.75 \%$ & 1.74 & $0.68^{\mathrm{a}}$ & - & $\begin{array}{l}\text { Liquefied corn } \\
\text { medium, } \\
184 \mathrm{~g} / \mathrm{L} \text { total } \\
\text { sugar, with } \\
0.2 \mu \mathrm{g} / \mathrm{mL} \text { anti- } \\
\text { mycin } \mathrm{A}, 72 \mathrm{~h}\end{array}$ & {$[76]$} \\
\hline
\end{tabular}

a Yield g/g sugar supplied

b Yield $\mathrm{g} / \mathrm{g}$ sugar reported in the literatures

\section{Enhancing precursor supplement pathway}

Acetyl-CoA and oxaloacetate are the two direct substrates for citric acid synthesis. Acetyl-CoA is generated by pyruvate dehydrogenase (PDH), cytosolic acetyl-CoA synthetase (ACS) and ATP-citrate lyase (ACL), and fatty acids beta-oxidization [67]. The production of acetyl-CoA by ACL consumes citrate, therefore, ACL should be considered not as precursor provider but product consumer. However, the function of ACL is currently unclear. Meijer et al. [68] showed that the deletion of acl1 in A. niger AB4.1 increased the organic acids including succinic acid and citric acid. Chen et al. [67] found that the deletion of two cytosolic ACL subunits (ACL1 and ACL2) in A. niger ATCC1015 resulted in decreasing citric acid production, concomitant with diminished asexual conidiogenesis, conidial germination and cell growth. In contrast, the overexpression exhibited reverse effects, suggesting that ACL is beneficial for citric acid accumulation. It was consistent with the time-series transcriptome analyses of citric acid fermentation, which speculated that the cytosolic ACL may involve in the ATP futile cycle [14].

Oxaloacetate is formed by pyruvate carboxylation in the cytoplasm and subsequently converted into malic acid. After entering the mitochondria through a malatecitrate shuttle, malic acid is reconverted into oxaloacetate and oxaloacetate takes part in citric acid synthesis. Therefore, de Jongh and Nielsen engineered the cytosol reductive TCA (rTCA) cycle by inserting heterogeneous malate dehydrogenase, fumarase and fumarate reductase [69]. It was found that overexpression of cytosolic fumarase FumR and cytosolic fumarate reductase Frds1 improved the citric acid yield and productivity, while overexpression of malate dehydrogenase Mdh2 only accelerated the initial production rate [69]. These results demonstrate the potential for introducing entire new biosynthetic pathways in $A$. niger, and highlight how novel industrial capabilities can be developed using systems metabolic engineering and synthetic biology. Indeed, the citric acid metabolic pathway may be entirely re-routed in the future and even synthesized in the cytoplasm instead of mitochondria.

\section{Reducing feedback inhibition}

Hexokinase is strongly inhibited by trehalose 6-phosphate [70]. However, the disruption of trehalose 6-phosphate synthase $(g g s A)$ only slightly led to the earlier 
initiation of citric acid accumulation and the final citric acid production was even reduced compared with the parent strain or multicopy transformant [71]. Legisa and Mattery speculated that assimilation of trehalose activated by cAMP-PKA signaling pathway at the early growth stage might relieve the inhibition of hexokinase, resulting in the glucose metabolism shift from pentose phosphate (PP) pathway to glycolysis, and concomitantly initiated citric acid accumulation [2].

PFK is another crucial controlling step for glycolysis metabolic flux via the allosteric inhibition or activation. ATP and citric acid are the inhibitors of PFK. Spontaneous post-translational modification plays a vital role in keeping the high activity of $A$. niger PFK1 [2]. In the study of Legisa and Mattey, the native PFK1 (85 kDa) was cleaved to an inactive fragment $(49 \mathrm{kDa})$ which could be reactivated by PKA phosphorylation. The shorter PFK1 fragment is not only resistant to citrate inhibition but also more susceptible to positive effectors, such as AMP, ammonium ions and fructose 2,6-bisphosphate, which suppresses the ATP inhibition. Based on this, Capuder et al. [72] designed an active shorter PFK1 fragment $m t$ $p f k A 10$ with T89D single site mutation to elude the phosphorylation requirement. A. niger TE23, constructed by overexpressing the active shorter PFK1 fragment in $A$. niger A158, exhibited citric acid production of $120 \mathrm{~g} / \mathrm{L}$ at $300 \mathrm{~h}$, about 70\% higher than the control strain [72].

\section{Regulating the respiratory chain}

In the citric acid synthesis pathway, the equivalent quantitative conversion of glucose to citric acid generated $1 \mathrm{~mol}$ of ATP and $3 \mathrm{~mol}$ of NADH. The NADH oxidization cycle by cytochrome-dependent respiration usually generated excess ATP, which strongly feedback inhibited PFK and impaired the glycolysis flux. Thus, when citric acid begins to accumulate, cytochrome-dependent respiration is replaced by the alternative route, which enables the NADH oxidization without concomitant ATP production [1, 4]. Wallrath et al. [73, 74] found that at the initiation of citric acid accumulation, activities of the cytochrome-dependent respiratory enzymes, especially for Complex I, decrease because of $\mathrm{Mn}^{2+}$ deficiency, whereas the AOX activity increases. Recently, some oxidative phosphorylation inhibitors, such as succinatecytochrome $\mathrm{c}$ inhibitor antimycin $\mathrm{A}$ or the oxidative phosphorylation uncoupler 2,4-dinitrophenol (DNP) [75]. Hou et al. [76] uncovered the overexpression of aox1 gene improve citric acid production up to $169.1 \mathrm{~g} / \mathrm{L}$ in the fermentation medium with antimycin A. Obviously, these studies pave the way for combined engineering of the cytochrome-dependent respiratory chain and alternative respiratory chain by promoter engineering.

\section{Engineering $\mathrm{Mn}^{2+}$ response and morphology}

$\mathrm{Mn}^{2+}$ deficiency plays a crucial role in citric acid accumulation. $\mathrm{Mn}^{2+}$ interferes with $A$. niger metabolism in several ways, for example by preventing citrate reutilization, suppressing macromolecular (protein, DNA, triglyceride and phospholipid) synthesis, enhancing protein degradation and intracellular $\mathrm{NH} 4{ }_{+}$concentration, altering the ratio of saturated: unsaturated fatty acid in the plasma membrane, modifying the polysaccharide concentration of the cell wall, and influencing morphology [4]. The Brsa-25 gene, which encodes a putative amino acid transporter, is involved in the regulation of morphology formation in response to $\mathrm{Mn}^{2+}$. Down-regulation of the Brsa-25 expression by antisense RNA reshaped the mycelial pellets and enhanced the citric acid production by $10 \%$ [77]. Similarly, RNA interference of the chitin synthase gene $(c h s C)$ also caused lower proportion of dispersed mycelia in the mycelial pellets and improved citric acid production about $42.6 \%$ [78]. $\mathrm{Mn}^{2+}$ response and morphology regulation are highly complex, and involve a large number of genes with different functions. Therefore, an efficient multiplex gene editing technology is in an urgent necessity for testing the synergistic effect and interaction of individual genes in a network.

\section{New generation techniques speed up systems metabolic engineering in $A$. niger}

Genetic and genomic manipulations exert a crucial influence in metabolic engineering of $A$. niger [79]. The rapid development of molecular genetic toolbox allows for and speeds up the realization of knowledge-driven, comparative omics-driven, and model-driven target predictions, thereby increasing the implement speed of systems metabolic engineering cycles. However, as described above, several key genes and metabolic pathways have been modified through the traditional transformation techniques to modulate the citric acid production and productivity. Although the gene targeting efficiency is improved in non-homologous end joining (NHEJ) deficient strains [80, 81], the first step for NHEJ deficient host construction, especially for industrially relevant isolates, and modifying genes in a high throughput manner is still very experimentally challenging and time-consuming.

Clustered Regularly Interspaced Short Palindromic Repeats/CRISPR associated protein (CRISPR/Cas) systems have become a very powerful genome editing technique [82, 83]. Recently, several CRISPR/Cas9 genome editing systems were established in A. niger (Fig. 2, Table 2) [84-89]. Nodvig et al. [84] reported the first CRIPSR/Cas9 system in Aspergilli sp. (Fig. 2a). They developed all-in-one single plasmid system combined the Cas9 expression cassette with sgRNA expression cassette 


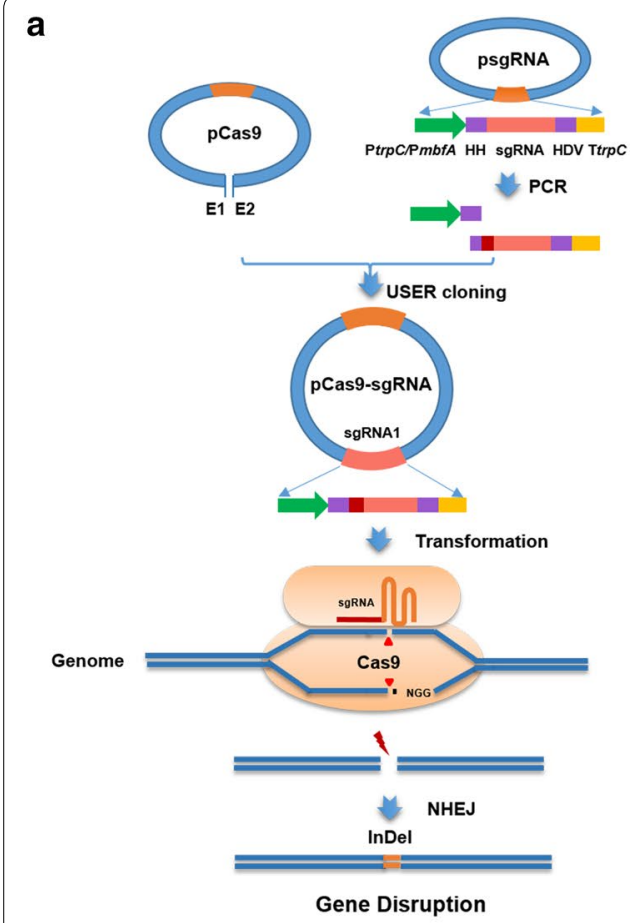

b
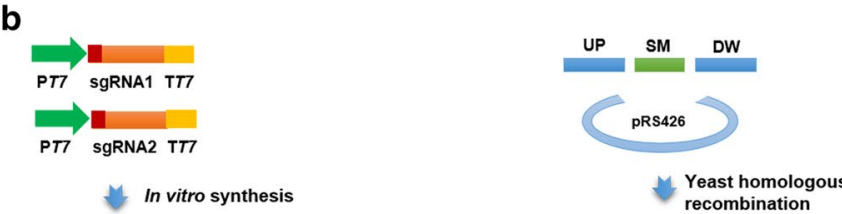

Yeast homologous

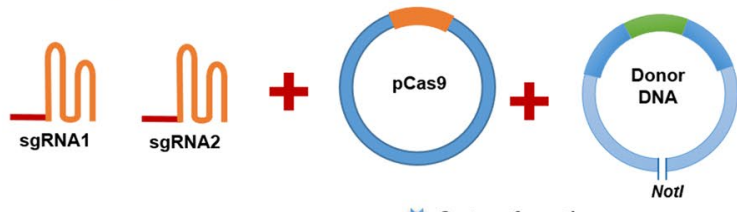

Co-transformation
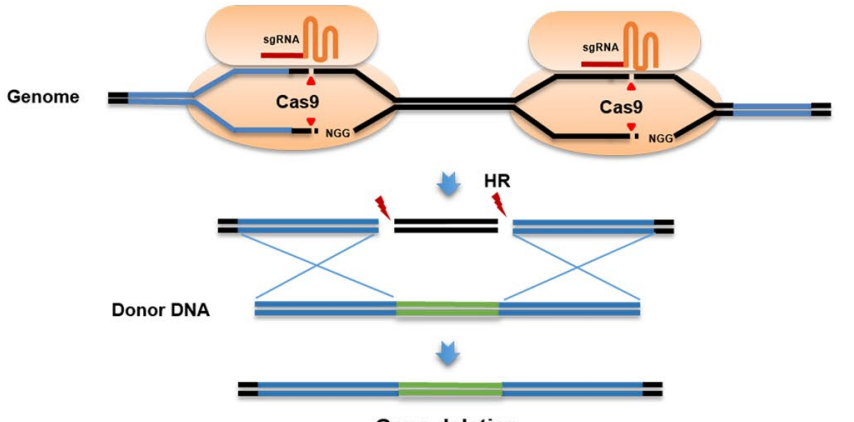

Gene deletion
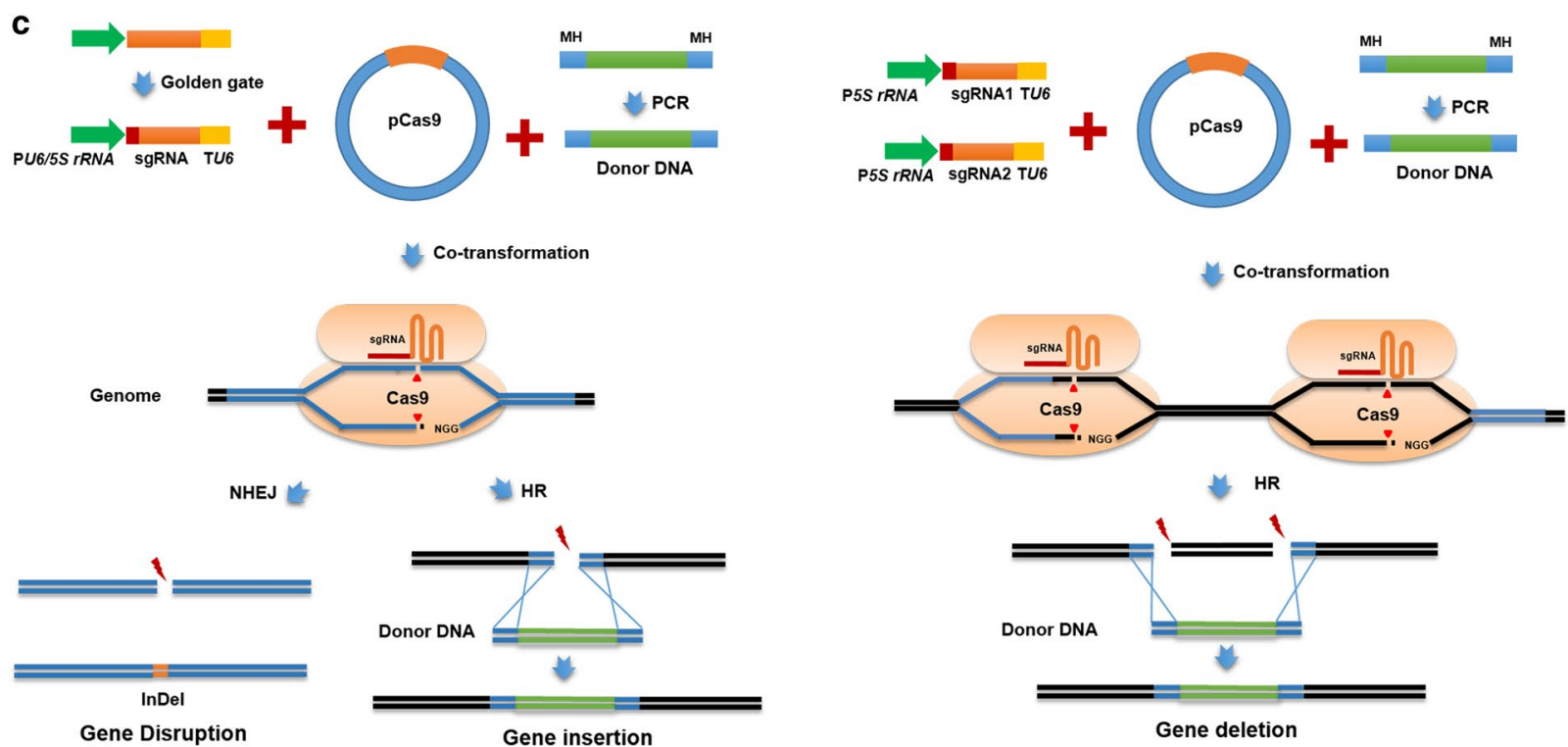

Fig. 2 CRISPR/Cas9 genome editing systems used in A. niger. a CRISPR/Cas9 system based on RNA polymerase II promoters for sgRNA expression enables the NHEJ-mediated gene disruption in A. niger [84]. $\mathbf{b}$ CRISPR/Cas9 system utilizing in vitro transcription for sgRNA synthesis enables the HR-mediated gene deletion with $1.5 \mathrm{~kb}$ homologous arm as donor DNA [85, 86]. c CRISPR/Cas9 systems based on RNA polymerase III promoters (U6 and $5 S$ rRNA promoters) for sgRNA expression facilitate the NHEJ-mediated gene disruption and HR-mediated gene insertion and deletion with 40 bp micro-homologous arms as donor DNA [88, 89]

using RNA polymerase II promoter PgpdA in a single vector. To ensure the matured structures of sgRNA, two ribozymes were added the $5^{\prime}$-end and $3^{\prime}$-end of sgRNA.
Although the system enables the NHEJ-mediated gene disruption, more cloning efforts and experimental workload are required due to the utilization of ribozymes 
Table 2 CRISPR/Cas9 genome editing systems used in A. niger

\begin{tabular}{|c|c|c|c|c|c|c|c|}
\hline \multicolumn{2}{|c|}{ sgRNA expression } & \multirow[t]{2}{*}{ Gene editing } & \multirow{2}{*}{$\begin{array}{l}\text { Donor DNA (SM/ } \\
\text { Homology arm size, } \\
\text { bp) }\end{array}$} & \multirow[t]{2}{*}{ Efficiency } & \multirow[t]{2}{*}{ Advantages } & \multirow[t]{2}{*}{ Limitation } & \multirow[t]{2}{*}{ References } \\
\hline Promoter & Terminator & & & & & & \\
\hline PgpdA & TtrpC & $\begin{array}{l}\text { NHEJ-mediated } \\
\text { gene disruption }\end{array}$ & - & Some & Less PAM limitation & $\begin{array}{l}\text { Requiring to add } \mathrm{HH} \\
\text { and } \mathrm{HDV} \text {, more } \\
\text { cloning effort }\end{array}$ & {$[84]$} \\
\hline In vitro synthesis & & $\begin{array}{l}\text { HR-mediated gene } \\
\text { deletion }\end{array}$ & pyrG/1500 & $28-100 \%$ & $\begin{array}{l}\text { Instantaneous } \\
\text { genome editing }\end{array}$ & $\begin{array}{l}\text { Hard to be used in } \\
\text { gene regulation, } \\
\text { dependent on } \\
\text { sgRNA uptake and } \\
\text { stability }\end{array}$ & {$[85]$} \\
\hline \multirow[t]{2}{*}{ Pmbfa } & \multirow[t]{2}{*}{ TtrpC } & $\begin{array}{l}\text { NHEJ-mediated } \\
\text { gene disruption }\end{array}$ & - & Some & \multirow[t]{2}{*}{ Less PAM limitation } & \multirow{2}{*}{$\begin{array}{l}\text { Requiring to add } \mathrm{HH} \\
\text { and } \mathrm{HDV} \text {, more } \\
\text { cloning effort }\end{array}$} & \multirow[t]{2}{*}[87]{} \\
\hline & & $\begin{array}{l}\text { HR-mediated gene } \\
\text { integration }\end{array}$ & pyrG/690 and 834 & $100 \%$ & & & \\
\hline PhU6 & \multirow[t]{4}{*}{ Ploy $(T)_{6}$} & \multirow{3}{*}{$\begin{array}{l}\text { NHEJ-mediated } \\
\text { gene disruption }\end{array}$} & - & $15 \%$ & \multirow[t]{4}{*}{ Less cloning effort } & \multirow[t]{4}{*}{ PAM motif ( $\left.G N_{19} G G\right)$} & \multirow[t]{4}{*}{ [88] } \\
\hline PyU6 & & & - & $20 \%$ & & & \\
\hline PanU6 & & & - & $23 \%$ & & & \\
\hline PanU6 & & $\begin{array}{l}\text { HR-mediated gene } \\
\text { integration }\end{array}$ & $h p h / 40$ & $36 \%$ & & & \\
\hline \multirow[t]{3}{*}{$5 S$ rRNA } & \multirow[t]{3}{*}{ Ploy $(T)_{6}$} & $\begin{array}{l}\text { NHEJ-mediated } \\
\text { gene disruption }\end{array}$ & - & $95.28-100 \%$ & \multirow{3}{*}{$\begin{array}{l}\text { High efficiency, less } \\
\text { cloning, less PAM } \\
\text { limitation }\end{array}$} & \multirow[t]{3}{*}{-} & \multirow[t]{3}{*}{ [89] } \\
\hline & & $\begin{array}{l}\text { HR-mediated gene } \\
\text { integration and } \\
\text { deletion }\end{array}$ & $h p h / 40$ & $100 \%$ & & & \\
\hline & & $\begin{array}{l}\text { Multiplex gene } \\
\text { editing }\end{array}$ & & $45.83 \%$ & & & \\
\hline
\end{tabular}

and sub-cloning of the final single vector. As an alternative solution, Kuivanen et al. [85, 86] adopted in vitro transcription using T7 promoters for sgRNA construction and then co-transformed the sgRNA with the Cas9 expressed plasmid into the protoplasts (Fig. 2b). This system was a suitable approach to achieve instantaneous genome editing, but the efficiency was influenced by the sgRNA stability and uptake [90]. Moreover, this strategy is not suitable for situations where the sgRNA gene needs to be expressed steadily or conditionally, such as CRISPR-AID system mediated transcriptional activation, transcriptional interference, and gene deletion [91]. To fill with the gap of $U 6$ promoter in A. niger, Zheng et al. [88] identified one endogenous $U 6$ promoter (PanU6) and tested the gene disruption efficiency of CRIPSR/ Cas9 system based on this PanU6 and other two heterologous U6 promoters (PhU6 and PyU6) (Fig. 2c). All the tested U6 promoters enabled guide RNA transcription and the gene disruption, but with low efficiency and few transformants. Zheng et al. [89] developed a novel CRIPSR/Cas9 system using $5 S$ rRNA gene to promote sgRNA synthesis. Dozens of transformants were obtained and the efficiency was significantly increased with $100 \%$ rates of precision gene modifications using short (40-bp) homologous donor DNA (Table 2, Fig. 2c). This system has been applied for chromosome design, as proven by multiplex gene insertion and large DNA fragment deletion to achieve a mycotoxin reduced chassis. This highly efficient CRISPR/Cas9 system facilitates chromosome design in $A$. niger, and allow for the genome manipulations in a high throughput and large-scale manner, thereby increasing the implemented speed of systems metabolic engineering cycle.

\section{Further prospects}

As mentioned above, the development of systems biology and genome editing technology paves the way to systemically engineer $A$. niger for citric acid production that is more environmentally friendly, with better food safety, and improved cost-effectiveness. A Learn-DesignBuild-Test (LDBT) cycle has been gradually established for customized metabolic engineering on a large-scale of $A$. niger, combining multi-omics analysis, computational biology approaches, molecular genetic manipulation toolbox and high through-put platform (Fig. 3). Namely, all the strategies for protein engineering, pathway engineering and strain engineering result from the deep learning of cell metabolism and regulation based on the genome information and multi-omics data (Learn, Fig. 3). The metabolic engineering targets are designed by knowledge-driven, comparative omics-driven, or in silico model-driven approaches (Design, Fig. 3). The designed 


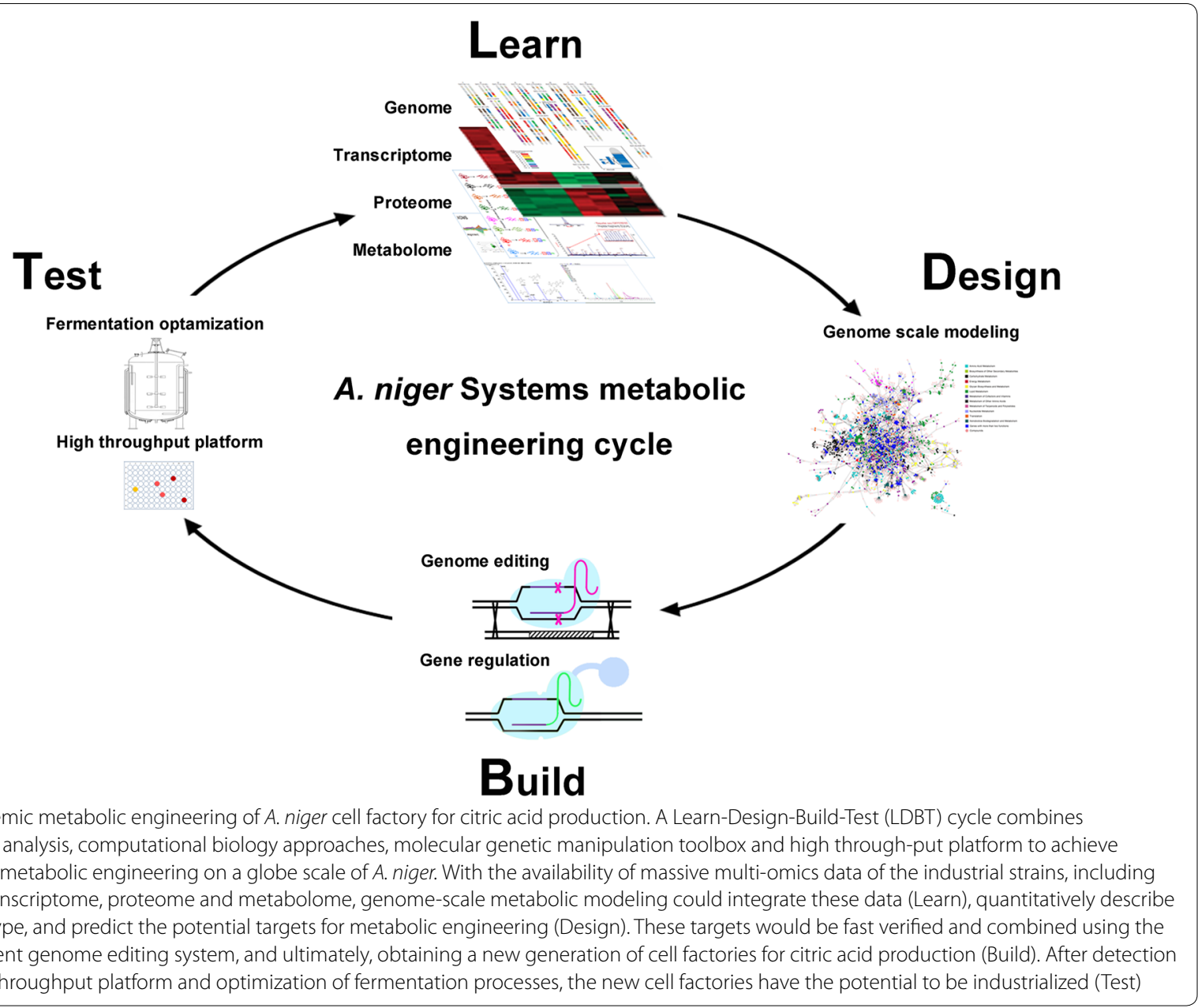

A. niger strains then would be constructed by genome editing and regulation toolboxes (Build, Fig. 3) and tested by comprehensive detection and fermentation optimization using high throughput platforms (Test, Fig. 3). To implement systems metabolic engineering cycle, we proposed several further challenges and prospects for each stage.

First, the massive multi-omics data provide the feasibility for understanding the $A$. niger at a systems-level. On one hand, to construct the stoichiometric and/or dynamic biological network, more absolutely quantitative omics data are required. On the other hand, the more efficient integrated approaches for multi-omics data are required to uncover the interactions among multi-omics data and the molecular regulation mechanism at different molecular levels, and ultimately to achieve the holistic design of new citric acid producing isolates meeting various requirements.

Secondly, until now, three metabolic engineering strategies have been developed for target prediction, including current knowledge-driven design, comparative omics-driven design, and in silico modeling design. Common knowledge-driven design strategies mostly focus on the improvement of precursor supplements, reduction of by-product formation and feedback inhibition, which are usually limited by the complexity of metabolic regulation. The comparative omics-driven design approach is suitable to distinguish the key genes contributed to specific phenotypes, in which the selection of intercomparable strains and condition design is of vital importance for target discovery. Otherwise, it is hard to find the key genes from the numerous potential differences. In contrast, genome-scale models facilitate to integrate multi-omics data and construct the organism-specific metabolic maps, interpret the changes of transcriptional and metabolic profiles, ultimately to establish a full understanding of the cell regulation complexity at different levels [92]. Most genome-scale metabolic models of $A$. niger have been developed for steady state, usually as stoichiometric models. In the future, a dynamic/kinetic model is required to illustrate the multi-omics and process data and predict the behavior of $A$. niger responding 
to interior and exterior changes during citric acid fermentation. Therefore, genome-scale metabolic modeling would become the main systems approach to optimize the metabolic engineering design.

Thirdly, to construct on-demand well-designed strains, three aspects should be paid more attention, including construction of synthetic biological module, construction of robust chassis and development of multiplex genetic manipulation toolboxes. CRISPR/Cas9 genome editing technology facilitates the rapid verification of new hypotheses and the realization of target predictions. Multiplex genome engineering and marker-free base editing are required to be established in $A$. niger to accelerate the systems metabolic engineering cycle for final industrialization.

Finally, high throughput platforms, including the spore collection, strain cultivation, metabolite detection and fermentation optimization, should be developed to test and screen the well-designed strains in a large-scale. All the exhaustive measurement data would be applied for the next strategy design.

\section{Conclusions}

With the rapid development of systems biology and synthetic biology, a major goal for the future of $A$. niger biotechnology is the generation of designer strains and super cell factory with higher titre, yield and productivity. Toward this end, some directions for systems metabolic engineering can be summarized as follows: improving the substrate utilization, removing by-product synthesis, removing negative feedback effect, enhancing the precursor supplement, enhancing the transport efficiency of substrates and citric acid, optimizing the NADH regeneration by regulating the respiratory chain, enhancing the robustness and resistance against environmental stress, regulating the morphology to fit the process operation. Many genome editing strategies could be applied to achieve metabolic engineering, including promoter engineering of target genes with inducible promoters, transcription factor engineering, transporter engineering, and transcription regulation via CRSIPRi/CRSIPRa system or RNAi. In conclusion, holistic design from multiomics analyses and dynamic modeling, genome editing combined with synthetic biology provide great promise for achieving rational design of $A$. niger at a system level.

\section{Additional file}

Additional file 1: Table S1. Genome information of several A. niger strains. Table S2. Metabolic engineering strategies for enhancing citric acid production in Yarrowia lipolytica.

\section{Abbreviations}

CRISPR: clustered regularly interspaced short palindromic repeats; Cas: CRISPR-associated proteins; sgRNA: single guide RNA; NHEJ: non-homologous end joining; HR: homologous recombination; NLS: nuclear localization signal; snRNA: small nuclear RNA; SNPs: single nucleotide polymorphisms; RNA-seq: RNA sequencing; PFK: phosphofructokinase; PDH: pyruvate dehydrogenase; ACS: cytosolic acetyl-CoA synthetase; ACL: ATP-citrate lyase; acetyl-CoA: acetyl-coenzyme A; NADH: nicotinamide adenine dinucleotide; GABA: $\gamma$-aminobutyric acid; DNP: 2,4-dinitrophenol.

\section{Authors' contributions}

JS and YT conceived the project. $\mathrm{ZT}$ and $\mathrm{XZ}$ designed and wrote the manuscript. JS, YT and Y-CS revised and finalized the manuscript. All authors read and approved the final manuscript.

\section{Author details}

${ }_{1}^{1}$ Department of Grain Science and Industry, Kansas State University, Manhattan, KS 66506, USA. ${ }^{2}$ Tianjin Institute of Industrial Biotechnology, Chinese Academy of Sciences, Tianjin 300308, People's Republic of China. ${ }^{3}$ Key Laboratory of Systems Microbial Biotechnology, Chinese Academy of Sciences, Tianjin 300308, People's Republic of China. ${ }^{4}$ COFCO Biochemical (Anhui) Co. Ltd, Bengbu 233000, People's Republic of China.

\section{Acknowledgements}

We thank Dr. Timothy C. Cairns for his help in improving this manuscript. This is contribution number 19-038-J from the Kansas Agricultural Experiment Station.

\section{Competing interests}

The authors declare that they have no competing interests.

\section{Availability of data and materials}

All data generated or analyzed during this study are included in this published article and its additional file. The authors are willing to provide any data and materials related to this research that may be requested for research purposes.

\section{Consent for publication}

Not applicable.

Ethics approval and consent to participate

Not applicable.

\section{Funding}

This work was supported by the National Natural Science Foundation of China (31700085 and 31370113).

\section{Publisher's Note}

Springer Nature remains neutral with regard to jurisdictional claims in published maps and institutional affiliations.

Received: 13 September 2018 Accepted: 16 January 2019 Published online: 04 February 2019

\section{References}

1. Karaffa L, Kubicek CP. Aspergillus niger citric acid accumulation: do we understand this well working black box? Appl Microbiol Biotechnol. 2003;61:189-96.

2. Legisa M, Mattey M. Changes in primary metabolism leading to citric acid overflow in Aspergillus niger. Biotechnol Lett. 2007;29:181-90.

3. Anastassiadis S, Morgunov IG, Kamzolova SV, Finogenova TV. Citric acid production patent review. Recent Pat Biotechnol. 2008;2:107-23.

4. Papagianni M. Advances in citric acid fermentation by Aspergillus niger: biochemical aspects, membrane transport and modeling. Biotechnol Adv. 2007;25:244-63.

5. Dhillon GS, Brar SK, Verma M, Tyagi RD. Recent Advances in Citric Acid Bio-production and Recovery. Food Bioprocess Technol. 2011;4:505-29.

6. Show PL, Oladele KO, Siew QY, Zakry FAA, Lan JCW, Ling TC. Overview of citric acid production from Aspergillus niger. Front Life Sci. 2015;8:271-83. 
7. Meyer V, Fiedler M, Nitsche B, King R. The cell factory Aspergillus enters the big data era: opportunities and challenges for optimising product formation. Adv Biochem Eng Biotechnol. 2015;149:91-132.

8. Singh R, White D, Demirel Y, Kelly R, Noll K, Blum P. Uncoupling fermentative synthesis of molecular hydrogen from biomass formation in Thermotoga maritima. Appl Environ Microbiol. 2018;84:e00998.

9. Meyer V, Andersen MR, Brakhage AA, Braus GH, Caddick MX, Cairns TC, de Vries RP, Haarmann T, Hansen K, Hertz-Fowler C, et al. Current challenges of research on filamentous fungi in relation to human welfare and a sustainable bio-economy: a white paper. Fungal Biol Biotechnol. 2016;3:6.

10. Becker J, Wittmann C. Systems and synthetic metabolic engineering for amino acid production - the heartbeat of industrial strain development. Curr Opin Biotechnol. 2012;23:718-26.

11. Becker J, Rohles CM, Wittmann C. Metabolically engineered Corynebacterium glutamicum for bio-based production of chemicals, fuels, materials, and healthcare products. Metab Eng. 2018;50:122-41.

12. Pel HJ, de Winde JH, Archer DB, Dyer PS, Hofmann G, Schaap PJ, Turner G, de Vries RP, Albang R, Albermann K, et al. Genome sequencing and analysis of the versatile cell factory Aspergillus niger CBS 513.88. Nat Biotechnol. 2007:25:221-31.

13. Andersen MR, Salazar MP, Schaap PJ, van de Vondervoort PJI, Culley D, Thykaer J, Frisvad JC, Nielsen KF, Albang R, Albermann K, et al. Comparative genomics of citric-acid-producing Aspergillus niger ATCC 1015 versus enzyme-producing CBS 513.88. Genome Res. 2011;21:885-97.

14. Yin $X$, Shin HD, Li J, Du G, Liu L, Chen J. Comparative genomics and transcriptome analysis of Aspergillus niger and metabolic engineering for citrate production. Sci Rep. 2017;7:41040

15. Mackenzie DA, Guillemette T, Al-Sheikh H, Watson AJ, Jeenes DJ, Wongwathanarat P, Dunn-Coleman NS, van Peij N, Archer DB. UPR-independent dithiothreitol stress-induced genes in Aspergillus niger. Mol Genet Genomics. 2005:274:410-8.

16. Andersen MR, Vongsangnak W, Panagiotou G, Salazar MP, Lehmann L, Nielsen J. A trispecies Aspergillus microarray: comparative transcriptomics of three Aspergillus species. Proc Natl Acad Sci USA. 2008;105:4387-92.

17. Salazar M, Vongsangnak W, Panagiotou G, Andersen MR, Nielsen J. Uncovering transcriptional regulation of glycerol metabolism in Aspergilli through genome-wide gene expression data analysis. Mol Genet Genomics. 2009;282:571-86.

18. Vikman P, Fadista J, Oskolkov N. RNA sequencing: current and prospective uses in metabolic research. J Mol Endocrinol. 2014;53:R93-101.

19. Wang B, Guo G, Wang C, Lin Y, Wang X, Zhao M, Guo Y, He M, Zhang Y, Pan L. Survey of the transcriptome of Aspergillus oryzae via massively parallel mRNA sequencing. Nucleic Acids Res. 2010;38:5075-87.

20. Delmas S, Pullan ST, Gaddipati S, Kokolski M, Malla S, Blythe MJ, Ibbett R, Campbell M, Liddell S, Aboobaker A, et al. Uncovering the genome-wide transcriptional responses of the filamentous fungus Aspergillus niger to lignocellulose using RNA sequencing. PLoS Genet. 2012;8:e1002875.

21. Daly P, van Munster JM, Blythe MJ, Ibbett R, Kokolski M, Gaddipati S, Lindquist E, Singan VR, Barry KW, Lipzen A, et al. Expression of Aspergillus niger CAZymes is determined by compositional changes in wheat straw generated by hydrothermal or ionic liquid pretreatments. Biotechnol Biofuels. 2017:10:35.

22. Ries L, Pullan ST, Delmas S, Malla S, Blythe MJ, Archer DB. Genome-wide transcriptional response of Trichoderma reesei to lignocellulose using RNA sequencing and comparison with Aspergillus niger. BMC Genomics. 2013;14:541.

23. van Munster JM, Daly P, Delmas S, Pullan ST, Blythe MJ, Malla S, Kokolski M, Noltorp ECM, Wennberg K, Fetherston R, et al. The role of carbon starvation in the induction of enzymes that degrade plant-derived carbohydrates in Aspergillus niger. Fungal Genet Biol. 2014;72:34-47.

24. Zhang H, Wang S, Zhang XX, Ji W, Song F, Zhao Y, Li J. The amyR-deletion strain of Aspergillus niger CICC2462 is a suitable host strain to express secreted protein with a low background. Microb Cell Fact. 2016;15:68.

25. Hagiwara D, Takahashi H, Kusuya Y, Kawamoto S, Kamei K, Gonoi T. Comparative transcriptome analysis revealing dormant conidia and germination associated genes in Aspergillus species: an essential role for AtfA in conidial dormancy. BMC Genomics. 2016;17:358.

26. Kwon MJ, Nitsche BM, Arentshorst M, Jorgensen TR, Ram AF, Meyer V. The transcriptomic signature of RacA activation and inactivation provides new insights into the morphogenetic network of Aspergillus niger. PLoS ONE. 2013;8:e68946.
27. van Munster JM, Nitsche BM, Krijgsheld P, van Wijk A, Dijkhuizen L, Wosten HA, Ram AF, van der Maarel MJ. Chitinases CtcB and CfCl modify the cell wall in sporulating aerial mycelium of Aspergillus niger. Microbiology. 2013;159:1853-67.

28. Schachtschabel D, Arentshorst M, Nitsche BM, Morris S, Nielsen KF, van den Hondel CA, Klis FM, Ram AF. The transcriptional repressor TupA in Aspergillus niger is involved in controlling gene expression related to cell wall biosynthesis, development, and nitrogen source availability. PLoS ONE. 2013;8:e78102.

29. Vesth TC, Brandl J, Andersen MR. FunGeneClusterS: predicting fungal gene clusters from genome and transcriptome data. Synth Syst Biotechnol. 2016;1:122-9.

30. Wang B, Lv Y, Li X, Lin Y, Deng H, Pan L. Profiling of secondary metabolite gene clusters regulated by LaeA in Aspergillus niger FGSC A1279 based on genome sequencing and transcriptome analysis. Res Microbiol. 2018;169:67-77.

31. Li A, Caspers M, Punt P. A systems biology approach for the identification of target genes for the improvement of itaconic acid production in Aspergillus species. BMC Res Notes. 2013;6:505.

32. Hu W, Li W, Chen H, Liu J, Wang S, Chen J. Changes in transcript levels of starch hydrolysis genes and raising citric acid production via carbon ion irradiation mutagenesis of Aspergillus niger. PLoS ONE. 2017;12:e0180120.

33. Alazi E, Knetsch T, Di Falco M, Reid ID, Arentshorst M, Visser J, Tsang A, Ram AFJ. Inducer-independent production of pectinases in Aspergillus niger by overexpression of the D-galacturonic acid-responsive transcription factor gaaR. Sci Rep. 2018;102:2723-36.

34. Lu X, Sun JB, Nimtz M, Wissing J, Zeng AP, Rinas U. The intra- and extracellular proteome of Aspergillus niger growing on defined medium with xylose or maltose as carbon substrate. Microb Cell Fact. 2010;9:1-13.

35. Adav SS, Li AA, Manavalan A, Punt P, Sze SK. Quantitative iTRAQ secretome analysis of Aspergillus niger reveals novel hydrolytic enzymes. J Proteome Res. 2010;9:3932-40.

36. Sloothaak J, Odoni DI, de Graaff LH, Dos Santos VM, Schaap PJ, TamayoRamos JA. Aspergillus niger membrane-associated proteome analysis for the identification of glucose transporters. Biotechnol Biofuels. 2015;8:150.

37. Sloothaak J, Odoni DI, Dos Santos VM, Schaap PJ, Tamayo-Ramos JA. Identification of a novel L-rhamnose uptake transporter in the filamentous fungus Aspergillus niger. J Am Soc Mass Spectrom. 2016;12:e1006468.

38. Causon TJ, Hann S. Review of sample preparation strategies for MS-based metabolomic studies in industrial biotechnology. Anal Chim Acta. 2016;938:18-32.

39. Engskog MKR, Haglof J, Arvidsson T, Pettersson C. LC-MS based global metabolite profiling: the necessity of high data quality. Metabolomics. 2016;12:114.

40. Ruijter GJG, Visser J. Determination of intermediary metabolites in Aspergillus niger. J Microbiol Methods. 1996;25:295-302.

41. Jernejc K. Comparison of different methods for metabolite extraction from Aspergillus niger mycelium. Acta Chim Slov. 2004;51:567-78.

42. Lameiras F, Heijnen JJ, van Gulik WM. Development of tools for quantitative intracellular metabolomics of Aspergillus niger chemostat cultures. Metabolomics. 2015;11:1253-64.

43. Zheng X, Yu J, Cairns TC, Zhang L, Zhang Z, Zhang Q, Zheng P, Sun J, Ma Y. Comprehensive improvement of sample preparation methodologies facilitates dynamic metabolomics of Aspergillus niger. Biotechnol J. 2018. https://doi.org/10.1002/biot.201800315.

44. Schmidt K, Norregaard LC, Pedersen B, Meissner A, Duus JO, Nielsen JO, Villadsen J. Quantification of intracellular metabolic fluxes from fractional enrichment and ${ }^{13} \mathrm{C}-{ }^{13} \mathrm{C}$ coupling constraints on the isotopomer distribution in labeled biomass components. Metab Eng. 1999;1:166-79.

45. Pedersen H, Christensen B, Hjort C, Nielsen J. Construction and characterization of an oxalic acid nonproducing strain of Aspergillus niger. Metab Eng. 2000;2:34-41.

46. Driouch H, Melzer G, Wittmann C. Integration of in vivo and in silico metabolic fluxes for improvement of recombinant protein production. Metab Eng. 2012;14:47-58.

47. Lu H, Liu X, Huang M, Xia J, Chu J, Zhuang Y, Zhang S, Noorman H. Integrated isotope-assisted metabolomics and ${ }^{(13)} \mathrm{C}$ metabolic flux analysis reveals metabolic flux redistribution for high glucoamylase production by Aspergillus niger. Microb Cell Fact. 2015;14:147. 
48. Stajich JE, Harris T, Brunk BP, Brestelli J, Fischer S, Harb OS, Kissinger JC, Li W, Nayak V, Pinney DF, et al. FungiDB: an integrated functional genomics database for fungi. Nucleic Acids Res. 2012;40:D675-81.

49. Andersen MR, Nielsen J. Current status of systems biology in Aspergilli. Fungal Genet Biol. 2009;46(Suppl 1):S180-90.

50. Alvarez-Vasquez F, Gonzalez-Alcon C, Torres NV. Metabolism of citric acid production by Aspergillus niger: model definition, steady-state analysis and constrained optimization of citric acid production rate. Biotechnol Bioeng. 2000;70:82-108.

51. Andersen MR, Nielsen ML, Nielsen J. Metabolic model integration of the bibliome, genome, metabolome and reactome of Aspergillus niger. Mol Syst Biol. 2008;4:178.

52. David H, Akesson M, Nielsen J. Reconstruction of the central carbon metabolism of Aspergillus niger. Eur J Biochem. 2003;270:4243-53.

53. Sun J, Lu X, Rinas U, Zeng A. Metabolic peculiarities of Aspergillus niger disclosed by comparative metabolic genomics. Genome Biol. 2007:8:R182.

54. Torres NV, Voit EO, Gonzalez-Alcon C. Optimization of nonlinear biotechnological processes with linear programming: application to citric acid production by Aspergillus niger. Biotechnol Bioeng. 1996;49:247-58.

55. Upton DJ, McQueen-Mason SJ, Wood AJ. An accurate description of Aspergillus niger organic acid batch fermentation through dynamic metabolic modeling. Biotechnol Biofuels. 2017;10:258.

56. Cairns TC, Nai C, Meyer V. How a fungus shapes biotechnology: 100 years of Aspergillus niger research. Fungal Biol Biotechnol. 2018;5:13.

57. Fu GY, Lu Y, Chi Z, Liu GL, Zhao SF, Jiang H, Chi ZM. Cloning and characterization of a pyruvate carboxylase gene from penicillium rubens and overexpression of the genein the yeast Yarrowia lipolytica for enhanced citric acid production. Mar Biotechnol. 2016;18:1-14.

58. Liu XY, Chi Z, Liu GL, Wang F, Madzak C, Chi ZM. Inulin hydrolysis and citric acid production from inulin using the surface-engineered Yarrowia lipolytica displaying inulinase. Metab Eng. 2010;12:469-76.

59. Liu XY, Chi Z, Liu GL, Madzak C, Chi ZM. Both decrease in ACL1 gene expression and increase in ICL1 gene expression in marine-derived yeast Yarrowia lipolytica expressing INU1 gene enhance citric acid production from inulin. Mar Biotechnol. 2013;15:26-36.

60. Forster A, Aurich A, Mauersberger S, Barth G. Citric acid production from sucrose using a recombinant strain of the yeast Yarrowia lipolytica. Appl Microbiol Biotechnol. 2007;75:1409-17.

61. Tan MJ, Chen X, Wang YK, Liu GL, Chi ZM. Enhanced citric acid production by a yeast Yarrowia lipolytica over-expressing a pyruvate carboxylase gene. Bioprocess Biosyst Eng. 2016;39:1289-96.

62. Ruijter GJ, Panneman H, Visser J. Overexpression of phosphofructokinase and pyruvate kinase in citric acid-producing Aspergillus niger. Biochim Biophys Acta. 1997;1334:317-26.

63. Ruijter GJ, Panneman H, Xu D, Visser J. Properties of Aspergillus niger citrate synthase and effects of citA overexpression on citric acid production. FEMS Microbiol Lett. 2000;184:35-40.

64. Ruijter GJ, van de Vondervoort PJ, Visser J. Oxalic acid production by Aspergillus niger: an oxalate-non-producing mutant produces citric acid at $\mathrm{pH} 5$ and in the presence of manganese. Microbiology. 1999;145(Pt 9):2569-76.

65. Yin X, Li J, Shin HD, Du G, Liu L, Chen J. Metabolic engineering in the biotechnological production of organic acids in the tricarboxylic acid cycle of microorganisms: advances and prospects. Biotechnol Adv. 2015:33(6):830-41.

66. Wang L, Cao Z, Hou L, Yin L, Wang D, Gao Q, Wu Z, Wang D. The opposite roles of agdA and glaA on citric acid production in Aspergillus niger. Appl Microbiol Biotechnol. 2016:100:5791-803.

67. Chen H, He XH, Geng HR, Liu H. Physiological characterization of ATP-citrate lyase in Aspergillus niger. J Ind Microbiol Biotechnol. 2014;41:721-31.

68. Meijer S, Nielsen ML, Olsson L, Nielsen J. Gene deletion of cytosolic ATP: citrate lyase leads to altered organic acid production in Aspergillus niger. J Ind Microbiol Biotechnol. 2009;36:1275-80.

69. de Jongh WA, Nielsen J. Enhanced citrate production through gene insertion in Aspergillus niger. Metab Eng. 2008;10:87-96.

70. Panneman H, Ruijter GJ, van den Broeck HC, Visser J. Cloning and biochemical characterisation of Aspergillus niger hexokinase-the enzyme is strongly inhibited by physiological concentrations of trehalose 6-phosphate. Eur J Biochem. 1998;258:223-32.

71. Arisan-Atac I, Wolschek MF, Kubicek CP. Trehalose-6-phosphate synthase A affects citrate accumulation by Aspergillus niger under conditions of high glycolytic flux. FEMS Microbiol Lett. 1996;140:77-83.

72. Capuder M, Solar T, Bencina M, Legisa M. Highly active, citrate inhibition resistant form of Aspergillus niger 6-phosphofructo-1-kinase encoded by a modified pfkA gene. J Biotechnol. 2009;144:51-7.

73. Wallrath J, Schmidt M, Weiss H. Concomitant loss of respiratory-chain $\mathrm{NADH}$-ubiquinone reductase (complex-i) and citric-acid accumulation in Aspergillus-niger. Appl Microbiol Biotechnol. 1991;36:76-81.

74. Wallrath J, Schmidt M, Weiss H. Correlation between manganesedeficiency, loss of respiratory-chain complex-i activity and citric-acid production in Aspergillus-niger. Arch Microbiol. 1992;158:435-8.

75. Wang L, Zhang JH, Cao ZL, Wang YJ, Gao Q, Zhang J, Wang DP. Inhibition of oxidative phosphorylation for enhancing citric acid production by Aspergillus niger. Microb Cell Fact. 2015;14:7.

76. Hou L, Liu L, Zhang H, Zhang L, Zhang L, Zhang J, Gao Q, Wang D. Functional analysis of the mitochondrial alternative oxidase gene (aox1) from Aspergillus niger CGMCC 10142 and its effects on citric acid production. Appl Microbiol Biotechnol. 2018;102(18):7981-95.

77. Dai Z, Mao X, Magnuson JK, Lasure LL. Identification of genes associated with morphology in Aspergillus niger by using suppression subtractive hybridization. Appl Environ Microbiol. 2004;70:2474-85.

78. Sun X, Wu H, Zhao G, Li Z, Wu X, Liu H, Zheng Z. Morphological regulation of Aspergillus niger to improve citric acid production by chsC gene silencing. Bioprocess Biosyst Eng. 2018;41:1029-38.

79. Meyer V. Genetic engineering of filamentous fungi-progress, obstacles and future trends. Biotechnol Adv. 2008;26:177-85.

80. Meyer V, Arentshorst M, El-Ghezal A, Drews AC, Kooistra R, van den Hondel CA, Ram AF. Highly efficient gene targeting in the Aspergillus niger kusA mutant. J Biotechnol. 2007;128:770-5.

81. Carvalho ND, Arentshorst M, Jin Kwon M, Meyer V, Ram AF. Expanding the ku70 toolbox for filamentous fungi: establishment of complementation vectors and recipient strains for advanced gene analyses. Appl Microbiol Biotechnol. 2010;87:1463-73.

82. Hsu PD, Lander ES, Zhang F. Development and applications of CRISPRCas9 for genome engineering. Cell. 2014;157:1262-78.

83. Sander JD, Joung JK. CRISPR-Cas systems for editing, regulating and targeting genomes. Nat Biotechnol. 2014;32:347-55.

84. Nodvig CS, Nielsen JB, Kogle ME, Mortensen UH. A CRISPR-Cas9 system for genetic engineering of filamentous fungi. PLoS ONE. 2015;10:e0133085.

85. Kuivanen J, Wang YMJ, Richard P. Engineering Aspergillus niger for galactaric acid production: elimination of galactaric acid catabolism by using RNA sequencing and CRISPR/Cas9. Microb Cell Fact. 2016;15:210.

86. Kuivanen J, Arvas M, Richard P. Clustered genes encoding 2-ketoL-gulonate reductase and L-idonate 5-dehydrogenase in the novel fungal D-glucuronic acid pathway. Front Microbiol. 2017:8:225.

87. Sarkari P, Marx H, Blumhoff ML, Mattanovich D, Sauer M, Steiger MG. An efficient tool for metabolic pathway construction and gene integration for Aspergillus niger. Bioresour Technol. 2017;245:1327-33.

88. Zheng X, Zheng P, Sun J, Kun Z, Ma Y. Heterologous and endogenous U6 snRNA promoters enable CRISPR/Cas9 mediated genome editing in Aspergillus niger. Fungal Biol Biotechnol. 2018;5:2.

89. Zheng X, Zheng P, Zhang K, Cairns TC, Meyer V, Sun J, Ma Y. 5 S rRNA promoter for guide rna expression enabled highly efficient CRISPR/Cas9 genome editing in Aspergillus niger. ACS Synth Biol. 2018. https://doi. org/10.1021/acssynbio.7b00456.

90. Pohl C, Kiel JA, Driessen AJ, Bovenberg RA, Nygard Y. CRISPR/Cas9 based genome editing of Penicillium chrysogenum. ACS Synth Biol. 2016:5(7):754-64

91. Lian J, HamediRad M, Hu S, Zhao H. Combinatorial metabolic engineering using an orthogonal tri-functional CRISPR system. Nat Commun. 2017:8:1688.

92. Brandl J, Andersen MR. Current state of genome-scale modeling in filamentous fungi. Biotechnol Lett. 2015;37:1131-9. 